\title{
Syncretistic Scientism and Dissonant Plausibility Structure: An Analysis of Worldview Orientation Among Generation Zers in South Korea
}

\author{
Steve Sang-Cheol Moon \\ Department of Intercultural Studies, Charis Institute for Intercultural Studies, Seoul, Republic of Korea
}

Email address:

moon@ciis.kr

\section{To cite this article:}

Steve Sang-Cheol Moon. Syncretistic Scientism and Dissonant Plausibility Structure: An Analysis of Worldview Orientation Among Generation Zers in South Korea. Humanities and Social Sciences. Vol. 9, No. 1, 2021, pp. 14-26. doi: 10.11648/j.hss.20210901.13

Received: January 6, 2021; Accepted: January 13, 2021; Published: January 25, 2021

\begin{abstract}
Generation Z ('Gen Z') is the generation of people born approximately between 1995 and 2010 as the children of Generation X ('Gen X') who were born between 1965 and 1980. Gen Z is the youngest generation with the older members of its group working in society after finishing formal education. This paper addresses the religious aspects of the Gen $\mathrm{Z}$ culture, focusing on the issues of worldview, plausibility structure, and worldview education. It is based on an empirical research project conducted in South Korea in 2020. The research methodology used was a constructivist grounded theory approach involving interviews of 30 people who were either Gen Zers or their religious educators. The study suggests three points concerning the ontological reflection of worldview, epistemological identification through contact points, and educational bridge-making in the mission of worldview education that is devoted to teaching the core and fundamental Christian doctrines about the world and life. First, Christian educators can understand the phenomena of syncretistic scientism among this new generation well when they approach them with faith and respect. It is important to make an ontological differentiation between the two generations that are different and heterogeneous at the worldview level. In contrast to the Gen X worldview that seems to be a mixture of modern scientism and a pre-modern tradition, the Gen $\mathrm{Z}$ worldview is a mixture of modern scientism and postmodern deconstructionism. Second, dissonant plausibility structures need epistemological contact points, which can be identified among cross-generational norms and values. Moving beyond identifying epistemological contact points, it is crucial to pursue an incarnational identification and find relevant ways to deliver a meaningful message to Gen $\mathrm{Z}$ in their preferred language of plausibility structure. Third, the relevant worldview education needs an educational bridging with a spirit and message of love. Christian educators need to teach the message of love in the spirit of love in order to be heard and help transform Gen Z's worldview. The above three points are essential Christian teachings and cross cultural and generational barriers because they are shared as common virtues between the two generations. The bridge-making for worldview education is possible when Christian religious educators properly understand and recognize the issues of syncretistic worldview orientations, dissonant plausibility structures, and creative educational approaches based on love. This needs a spirit and message of faith, hope, and love to be relevant in ministry.
\end{abstract}

Keywords: Generation Z, Worldview Education, Religious Education, Worldview Transformation, Korean Studies

\section{Introduction}

Generation Z ('Gen Z') is the generation of people born approximately between 1995 and 2010. Gen Z succeeds Generation Y, also called Millennials, who were born between 1981 and 1996. Gen Zers are the children of Generation X ('Gen X') who were born between 1965 and 1980 [1]. Gen $\mathrm{Z}$ is currently the youngest generation with the older members of its group working in society after finishing formal education. According to the Organisation for Economic Co-operation and Development (OECD), the number of Gen Zers reached over 2 billion in 2019, comprising more than 30 percent of the world's population. In South Korea, Gen Zers account for 21.7 percent of all consumers [2], and an analysis of big data showed a 40 percent increase in the comments on Gen $\mathrm{Z}$ online in the 
fourth quarter of 2017 [3]. Moreover, in South Korea, the ratio of Video on Demand (VoD) users is highest among Gen Zers [4].

The phenomena of Gen $Z$ could be viewed from different perspectives, but this article addresses the religious aspect with a focus on the issues of worldview, plausibility structure, and worldview education. The concept of worldview is not just metaphysical, but also involves thinking about many realistic and practical life issues. Clifford Geertz defines it as people's picture of the way things in actuality are, their concepts of nature, self, and society, and the most comprehensive ideas of order [5]. It can be considered a subject of cultural studies although there is a certain a priori dimension in its definition. Particularly, both the notion of worldview universals suggested by Michael Kearney [6] and the suggested method for empirical research by Paul G. Hiebert need to be harnessed in an interdisciplinary study of worldview [7].

The concept of plausibility structure also has an empirical dimension since it was originally suggested in Peter Berger's seminal book The Sacred Canopy: Elements of a Sociological Theory of Religion published in 1967. Berger understood plausibility structure as a social "base" each world requires for its continuing existence as a world that is real to human beings [8]. Lesslie Newbigin's argumentation further developed one of Berger's points that the pluralistic situation multiplies the number of plausibility structures competing with each other. Newbigin appropriated Berger's term of plausibility structure succinctly by discussing the theological mandate in a pluralistic society in his two books, Foolishness to the Greeks: The Gospel and Western Culture published in 1986 and The Gospel in a Pluralist Society published in 1989 [9]. These notions of worldview and plausibility structure are important in understanding Gen Zers from a religious perspective.

Worldview education does not only aim at teaching the core doctrines of Christianity such as the Creation and the sovereignty of God, the Fall and the fallen nature of man, the Redemption and the saving grace of God, and the End of the world and eternity. It also seeks to suggest ways to integrate faith and life and further to integrate theology and other disciplines in Christian learning and practices from the beginning. This stream of Christian worldview studies is more philosophically driven in theology and needs to be integrated with anthropological insights to harness interdisciplinary understanding. The current stream of worldview education would need to consider and reflect the characteristics of Gen Zers' worldview and plausibility in order to be relevant in ministry.

Up to now, not many studies have addressed this issue of worldview orientation through empirical studies. There are several resources on the Gen $\mathrm{Z}$ culture from a marketing perspective, but little has been written in South Korea. Though the United States has more resources concerning Gen $\mathrm{Z}$, even here there are limitations. Barna Group and Impact 360 Institute's observations are solidly based on statistical analysis, but the qualitative study is only supplementary and not systematic enough [10]. Mark Beal's book well summarizes important lessons to be applied in relating to Gen Zers, but they are more intuitive than based on rigorous analysis. The book by Richard Dool and a team of Gen Z coauthors is helpful in terms of understanding how Gen Zers want to be led, but its points need to be verified though scientific studies to be justified. Corey Seemiller and Meghan Grace's book deepens the knowledge about Gen Z's learning style and related issues, but its findings might need an intercultural analysis and comparison. James Emery White's book richly and impressively reflects the author's personal observations and insights, but needs verification through systematic research. A systematic qualitative study, especially from a comparative angle is much needed to advance the knowledge about Gen Zers in different contexts.

This article is the report of an empirical research project that was conducted by the present author between March 1 and December 31, 2020 in South Korea. The purpose of the study was to analyze the characteristics of Gen Zers' worldview and plausibility structure from the perspective of a Christian worldview education in a South Korean context. The purpose of the research can be further categorized into three research questions:

(1) What characteristics does the worldview of Gen Zers reflect in relation to scientism?

(2) What characteristics does the plausibility structure of Gen Zers reflect in relation to epistemology? [11]

(3) What characteristics does a Christian worldview education need to reflect for Gen Zers?

The study is a qualitative research involving interviews of 20 Gen Zers and 10 religious educators who teach them. The proposal for the empirical research was prepared and revised several times from March 1 through June 30, 2020, and the final version was approved by the Public Institutional Review Board that belongs to the Ministry of Health and Welfare in South Korea on July 1, 2020. The subsequent procedure of data gathering was carried out by interviewing the 30 people between July 7 and November 14, 2020. The interviews were conducted via live video conference considering the restrictions on in-person meetings due to the Covid-19 pandemic. The gathered qualitative data was analyzed by November 30, 2020 before writing this report.

\section{Research Methodology}

The overall methodology for this study was based on a grounded theory approach, especially that of a constructivist paradigm. Theoretically, the suggestions in Kathy Charmaz' revised book published in 2014 were considered positively. The concrete procedures of the methodological approach, however, were designed based on the present author's experience.

\subsection{Procedure of Data Gathering}

The data was gathered by interviewing 20 Gen Zers and 10 educators who teach religious education to this generation, making a total of 30 people interviewed. The ages of the Gen 
Zers interviewed were between 18 and 25. Among the 20 Gen Zers, ten were Christian and the remaining 10 were nonreligious. Half were men and half were women. Four were employed workers who had finished their formal education, and the rest were university students. Half of the ten Christian educators were working in a local church, whereas the other half were working with Christian organizations devoted to campus ministries. Half were male and half were female.

Each interview lasted about one hour using solutions for live video conference such as Zoom and Kakao Face Talk. The interview sessions were voice recorded, but not video recorded. The recordings were transcribed in Korean on Microsoft Word according to the principle of verbatim.

The points of data gathering were as follows:

(1) Religious background and identity

(2) Understanding about the principle and causality of the universe and the world

(3) Subjective understanding of causality on what is happening in the interviewee's life

(4) Usefulness of scientific theories and knowledge in understanding what is happening in the world

(5) Subjective understanding about the usefulness of scientific theories and knowledge in finding the meanings of life and accordingly making important decisions based on them

(6) Individual criteria for judging the plausibility of truth claims

(7) Individual criteria for judging the plausibility of truth claims that contain religious messages

(8) Evaluation of the plausibility of religious messages in general (including sermons and evangelistic messages)

(9) Ways for religious educators to improve the plausibility of religious messages

(10) Ways for churches and Christian organizations to improve the plausibility of religious messages.

The total length of interview recordings was 24 hours 4 minutes 14 seconds. The minimum length of a single interview was 30 minutes 4 seconds, and the maximum was 1 hour 8 minutes 3 seconds. The total length of the Interview notes was 22,198 words. Individually, the minimum length was 411 words and the maximum was 1,288 words.

\subsection{Procedure of Data Analysis}

The transcribed interview notes were imported in NVivo, the QSR software for qualitative data analysis, for a systematic analysis. The data was analyzed systematically to identify patterns of themes and eventually formulate theoretical findings. They were then logically generalized. The analytical procedures were customized for this study, but reflected the suggestions of Charmaz in principle [12].

The first stage of data analysis in NVivo was conducted with the initial coding. It was a line-by-line coding that summarized the statements into a word or a short phrase. Through this, the remarks were summarized into relevant codes (or nodes in the software). Effort was made to identify an emerging central concept in each stage of analysis, paying attention to the emerging patterns of themes.

The second stage of data analysis in NVivo centered on focused coding. In this process, attention was given to the codes that were directly and repeatedly related to the core domains of the research questions. Through NVivo the frequency of the codes were effectively checked. This process analyzed how important themes were reiterated by the research participants. The key was to identify the central concepts that emerged when analyzing the data.

The third and final stage was the theorizing process along with theoretical coding. There was a move from the identification of patterns of repeated themes and central concepts toward theoretical synthesizing. The focal point of this stage was to identify the overarching concept that can synthesize the central concepts emerged through the data analysis.

\section{Result of Data Analysis}

The result of the data analysis is shown below according to the three stages of coding. These procedures moved from a descriptive toward a generative analysis.

\subsection{Initial Coding and Descriptive Analysis}

The first stage of data analysis according to the initial coding was descriptive, but identified important themes related to the characteristics of the Gen $\mathrm{Z}$ culture.

\subsubsection{Initial Coding}

The process of initial line-by-line coding ended with a total of 96 codes (or nodes in NVivo). Of them, 23 codes were categorized as general observations composed of themes not directly related to any particular research question. The other 73 codes were directly related to the research questions: 18 belonged to question one with themes related to scientism; 29 belonged to question two with themes addressing plausibility structure; and 26 belonged to question three with themes about effective educational approaches.

\subsubsection{General Observation}

A total of 23 codes belong to the category of general observation about Gen $\mathrm{Z}$ characteristics. Among them, 12 were mentioned in common by three or more research participants. These repeated themes were primarily analyzed, but the other codes were also considered in the analysis.

It was observed that Gen Zers tend to adjust well to social norms and pressures on one hand, but also question traditions and customs on the other. They also feel a pressure from their peers to lean toward certain opinions and postures (Interview 26). They find themselves to be significantly different from previous generations, which seems to be a contributing factor to the severe intergenerational conflicts in society. Gen Zers want to be respected as they are (Interview 27). They do not want to be unfairly judged by the criteria of older generations. It is crucial for them to be recognized as a different generation, according to the interviewees.

Gen Zers find that they are very different among 
themselves (Interviews 3, 7). This generation has a lot of internal variation as well as external differences with previous generations (Interviews 3, 4, 5). They seem to be less homogeneous and cohesive than other generations in their generational culture (Interview 9). This phenomenon can be attributed to different parenting styles and family backgrounds. Due to this internal variation, many Gen Zers value respecting differences and idiosyncrasies among themselves. As such, paying attention to individual opinions and perspectives is necessary to effectively motivate and work with them. Uniformity in a collective culture is being severely challenged in this new generation in South Korea. It has been pointed out that Gen $\mathrm{Z}$ will be the last generation to maintain a certain level of generational commonalities and cohesion in the United States, which also seems to be the case in South Korea [13]. Intra-generational heterogeneity were significantly observed and talked about throughout the interviewing process.

Gen Zers tend to be individualistic rather than collective and community-oriented (Interviews 4, 6, 26, 27, 28, 29). Individual perspectives were taken for granted among them, which has to do with their background in a nuclear family [14]. Their perspectives have not been challenged by others from their childhood. More often than not, they are an only child and much focus was given to their desires when growing up. Many Gen Zers had both parents working, and they were left to pass the time by themselves (Interview 29). They were used to watching TV or playing on the smart phone alone. It is normative not to harm others or be harmed by others for this individualistic orientation (Interview 30). Older generations might interpret this characteristic of individualism as egocentrism, but Gen Zers think they are only clear about what they want. They are sometimes called the YOLO ('You only live once') generation with their consumerism and hedonism of a this-worldly orientation (Interview 7). Their basic tenets have to do with emphasis on personal time and privacy, which is justified as a means of protecting themselves in society (Interview 7). This individualism is reinforced by their preferred way of social communication through SNS (Interview 29). Their expressions and way of communication are not inhibited like the previous generations, and the collective nature of the Korean culture seems to erode phenomenally in this generation. Of the 30 interviewees, 12 highlighted this aspect of Gen Zers in a major way.

Many Gen Zers understand that social incidents happen as a result of interpersonal relationships (Interviews 3, 11, 12, 13, 16, 19). Especially, the affective dimension is valued highly among them. Meeting with a person is considered a significant beginning or turning point in their lives. To Gen Zers, things happen around people. Making the right decision is important, so they find it hard to make a big decision on their own. They are conscious of other people to some degree, but are more sensitive to their peer group's perspectives and opinions as they are easy to reach through different means of communication, i.e. SNS (Interviews 24, 27). Interpersonal relationship is never overlooked in this generation, but it is emphasized in a new form. There is a tendency for individualism, but the recognition of diversity within the generation alerts them to be sensitive to others. This cautious posture balances individualism and collectivism in a subtle way. Nine of the interviewees noted this emphasis on interpersonal relationship among Gen Zers.

Flexibility is another characteristic of Gen Zers in South Korea (Interviews 11, 12, 13, 18). The traditional Confucian thought leans toward rigid observance of norms and regulations, but this generation emphasizes flexibility in applying traditional rules (Interview 12). Young people think that they are more open-minded and attempt at new things. Many Gen Zers make decisions based on what they see and hear, which are liable to change. They generally do not believe in absolute external principles, but think much is based on individual judgment and choice (Interview 18). For example, many Christian Gen Zers do not agree on the conservative churches' traditional restrictions on drinking alcohol and smoking, although the restrictions have been accepted as normative among older Christians. In some cases, Christian Gen Zers are more flexible on sexual ethics as well. This flexible mind can also mean an openness to other perspectives and standpoints, even toward a religious conversion and renewed lifestyle that have been restricted in traditional societies. This aspect of flexible thinking could also be interpreted as a coping mechanism in a conflictual society. Eight of the participants referred to this theme of flexible thinking.

Many Gen Zers were affected by two nationwide financial crises in their lives up to now. Firstly, the Asian financial crisis that started in 1997; and secondly, the Great Recession that started in 2007. Many families long suffered from economic losses and instabilities. Many Gen Zers remember spending time before the TV alone or with another sibling because both of their parents worked (Interviews 16, 22, 29). Their parents' mental and psychological conditions seem to have affected them in a significant way. Demanding school work and pressures for university entrance exams may have aggravated a tendency of helplessness and furthered selfprotective defense mechanisms (Interviews 10, 13). The sinking of MV Sewol in 2014 was another traumatic experience to this generation since it involved the death of 304 people who were mostly high school students. One interviewee said their generation is 'a generation of suffering,' pointing out that they were more emotionally damaged by disasters of one kind or another and additionally struggling more with exams and lower levels of income than previous generations (Interview 10). Several other interviewees shared this kind of sad feeling about what they experienced as a generation.

There was an observation that many Gen Zers have impressive leadership potentials in terms of teamwork and collaboration, according to Richard Dool and his Gen Z coauthors [15]. A similar point can be made about Korean Gen Zers only with the condition that they have overcome a deep seated sense of frustration. It appears that many Korean Gen Zers have internal strength to cope with hardships and 
difficulties in life which gives them the boldness and courage to make new attempts fearlessly. One Christian educator emphasized that some Gen Zers, when encouraged and empowered through mentoring and coaching, realize their leadership potentials to overcome an inhibited and passive mindset (Interview 22).

One of the reasons why Gen Zers have good leadership potential and are competent is that their parents are not helicopter parents always hovering over their children, according to White [13]. In this Korean study, at least four of the ten educators noted that the parenting style of Gen Xers, who are the parents of Gen Zers, in South Korea are still like helicopter parents. Some even think that such a tendency of controlling parenting is worse than the previous generations (Interview 21). Gen Zers have freedom, but within a certain boundary. So realistically, they cannot make important decisions totally free from family pressures (Interview 23). Emotional control and dependency are distinctly at the core of the psychological unrest (Interview 24). Yet many parents of Gen Zers are more informed and understand how to rear their children to be emotionally strong and cognitively competent. In such cases, the children exhibit good leadership potential regardless of the negative conditions in the family environment.

It is observed that Korean Gen Zers are sensitive and try to adjust themselves to changes and developments in the world. Time pressure is real for this generation as they seek opportunities for further education and employment
(Interviews 9, 12, 13). Their opinions can easily change with an influx of new information. They generally pursue stability in life, and thus might not be interested in making a big sacrifice and commitment to any religious or ideological cause (Interviews 2, 21). Instead, they are interested in selfrealization and satisfying their own needs and expectations. Some of the interviewed Christian educators are seeing increasing cases of Gen Zers suffering from mental illness in comparison to the previous generations (Interviews 26, 30). It is also observed that many Gen Zers are struggling to enhance their ability to adjust to organizational expectations when employed (Interview 24).

Corey Seemiller and Meghan Grace have pointed out that the facilities for learning need to be quiet, clean, and comfortable for this generation [16]. This is generally true with Korean Gen Zers as well (Interviews 21, 22, 25). Their expectation level is much higher than previous generations, and they expect facilities for group activities to be more convenient and comfortable. They also seem to spend more money on physical and emotional comforts than the previous generations. Generally speaking, they pursue small scale satisfaction rather than meta-narratives.

The central concept in this initial coding and analysis might be to phenomenologically understand the cultural differences of Gen Z. It is a good starting point to understand how they are different as a generation. The result of the data analysis up to this point is summarized in Table 1.

Table 1. Initial coding-general.

\begin{tabular}{llll}
\hline Process & Category & Theme (repeated) & Central concept \\
\hline Initial coding & General & $23(12)$ & To phenomenologically understand differences \\
\hline
\end{tabular}

\subsection{Focused Coding and Structural Analysis}

The focused coding will address important themes directly related to the probes of the research questions one by one. The codes that have been repeated by three or more interviewees took priority, but other codes were also considered in the analysis.

\subsubsection{Scientism and Worldview Orientation}

The first research question and its related probes have to do with scientism. A total of 18 codes were categorized to this issue. Of them, 11 were repeated by three or more interviewees, to which more focused attention was given. The less frequent codes, however, were also reflected in the data analysis.

Gen Zers were born during the same period as some of their favorite brands - Google (1998), iTunes (2003), Twitter (2006), Uber (2009), Instagram (2010) — and grew up with them as digital natives [17]. Several of the interviewed Gen Zers agreed that they are generally faster and more competent in using digital technologies than the older generations. They have a stronger desire to consume and reproduce digital contents since they became familiar with online and mobile technologies in their childhood. Their preference of VoD such as YouTube contrasts with their parents who are used to watching TV. They also think that they rely on printed materials less than the previous generations do. SNS has become one of their main means of interpersonal communication.

Gen Zers tend to consider science and technology to be important in their lives. At least six of the Gen $\mathrm{Z}$ interviewees affirmed the importance and usefulness of science and technology. They are not only affirmative about natural sciences, but also about the social sciences. Some of the interviewees felt they faced problems and conflicts when they were too emotionally driven in making decisions, and learned the importance of making scientific judgments (Interview 2). The reason why scientific knowledge and theories are important is because they are evidentially proven. Some Christians believe that scientific laws are not inconsistent with God's laws in this world, which can be further proven as scientific knowledge advances (Interview 6). To many Gen Zers it is considered a wisdom of life to utilize scientific knowledge in everyday life.

At a deeper level, Gen Zers show a scientistic orientation in their worldview. It is not just a matter of wisdom for living, but also a matter of a priori outlook about the world and life. Their basic understanding of the world and the universe is 
rooted in scientific knowledge, although its limitation is recognizable. To many of them, scientific knowledge generally takes precedence over a religious truth claim when these two lines of thinking conflict with one another (Interview 15).

This scientistic orientation is more prominent among Gen Zers than in previous generations because there are more scientific indicators available now. On the other hand, Gen Zers are more cautious and discrete in applying scientific information probably because they recognize its limitations based on insufficient information. Nevertheless, they generally believe that it is wise and reasonable to use scientific knowledge and technological information. Some of the interviewees even claimed that scientific knowledge is useful in finding the meanings of life. They basically trust objective findings based on experiments and systematic studies (Interview 20). Along this line, some Christians accept theistic evolutionism in an effort to integrate science and religion, which is commonly rejected by conservative theologians in South Korea.

This kind of scientism is reinforced by formal education at school. In some sense, Gen Z Christians are more affected by secular school education than by the religious education of churches and Christian organizations. In understanding causality, science is more influential than religion among Gen Zers in South Korea. Gen Zers tend to accept scientific explanations, including those on the beginning of world and life (Interview 3). This tendency is more so among the nonreligious. Many Christians find it hard to narrow the gap between science and religion even in the fundamental view of the Creation (Interview 9).

Another practical reason for scientistic thinking is that it enables prediction and preparation for the future (Interview 15). People think they can prepare well as they utilize concrete scientific knowledge. For many, scientism is overall a pragmatic standpoint that seems to promise tangible solutions for many questions and issues in life. This perspective is permeated to the deepest level of worldview in that many of the presuppositions are assumed a priori givens not questioned explicitly. Of the interviewees, 18 referred to this kind of scientistic orientation mostly affirmatively.

Many Gen Zers, especially the nonreligious, have reflected an activistic understanding of causality, which contrasts with the theistic understanding of fundamental causality among Christians. Even among Christians, many think that what they achieve is based on their earlier efforts and inputs. Overall, Gen Zers share the view that things are dependent on what they do, which has been reinforced through their life journey. For this reason they feel a lot of pressure in making decisions and choosing a course of action. Along the same line, they tend to emphasize the cause of caring for the environment. They think people should observe environmental ethics to preserve quality of life for the future.

It has almost become a habit for Gen Zers to check factual truth before making any judgment. They accept truth claims that are judged as factually truthful. This tendency was reinforced by their exposure to the phenomenon of datageddon. One way of checking the factuality also has to do with logic. Gen Zers are apt to accept certain positions when they are presented logically. The logical presentation most likely includes a scientific foundation or evidence that is sometimes statistical data. The logical foundation often aligns with professional authority. Claims by authorities tend to carry more weight in this scientistic worldview orientation. Expert study reports are rarely questioned. Even in everyday life, Gen Zers crosscheck other people's feedback as well as expert recommendations (Interview 27). A total of 11 interviewees emphasized this aspect of scientistic practice.

It is also observed that in many cases, Korean Gen Zers are keen on problem-solving. Korea is traditionally a monocultural society, and the older generations were somewhat inhibited from intercultural settings overseas. But this has changed dramatically in recent years. Christian educators who have been training university students through intercultural exposure programs find their trainees highly competent in their performance in an intercultural setting (Interviews 23, 25). Gen Zers perform well without fear of overseas assignments, using advanced technologies and media appropriately, which contrasts with the older generations.

One of the reasons for the higher competence and performance is that this generation is selective in choosing their areas of interest. They show focused attention on matters they choose to learn while totally neglecting those that do not interest them. One interviewee observed that the algorithms of AI such as YouTube could be a viable factor that contributes to this phenomenon. The high educational standard in South Korea is another factor that contributes to the interest in specialists and expertise. The result is a highly compartmentalized accumulation of knowledge among many Gen Zers.

Many of the interviewees agreed on the limitation of scientific theories in one way or another, with 16 commenting on this issue affirmatively. They made it clear that scientific knowledge is not helpful in dealing with the ultimate questions. Their basic understanding is that science is useful, but an absolute dependence on it is dangerous. Scientific knowledge can be misused and can undermine human dignity because the knowledge is not flawless and cannot relevantly address the ultimate questions of life such as the meaning of existence. Many problems in life are social and relational, which cannot be resolved scientifically, one interviewee emphasized (Interview 8).

Due to the limitations of science, the scientistic worldview orientation loses balance. One such aspect is materialism. The scientistic worldview seems to sound logical and reasonable, but in practice it centers on money. Some Gen Zers prioritize earning money through part-time work in order to continue their daily routine of consumption. Seeking employment is the core concern for many, and checking the profitability or reward before making a decision is a norm. One religious educator observed that Gen Zers do not want to make any sacrificial religious commitments at the expense of a prosperous future. When Gen Zers find new opportunity, 
they could leave the company or organization they belong to more easily than the previous generations. They might appear to have weak organizational loyalty. In extreme cases, they could reflect a phenomenon of solipsism that shows strong self expression, dissatisfaction about job description, and occasional emotional explosions (Interview 24, 30).

Scientism lacks a metaphysical dimension and is void of an essential element of worldview. A scientistic worldview cannot stand on its own, and alternatively tries to fill the vacuum by supplementing from external sources. A core observation about the scientistic worldview of Gen $\mathrm{Z}$ in South Korea is that it is mixed with other religious traditions, streams of thought, or philosophical paradigms. When it is mixed with pre-modern religious traditions, this generation embodies a theistic understanding of causality at the core of their worldview (at least 9 interviewees reflected this kind of cognition). Mixed with current tides of thought, some interviewees reflected a postmodern synthesis of scientism (at least 6 either reflected or commented on this theme). In this case, the Gen Zers do not care about consistency in worldview themes, accepting the heterogeneity within it as it is (Interviews 23, 29). They do not raise any questions about such deconstruction and dissonance. In this position, Gen Zers synthesize rationalism and emotionalism. Rarely do some mix scientism with a more refined philosophical paradigm such as critical realism to keep a balance between modern and postmodern paradigms. Gen Zers tend to judge public issues objectively and scientifically, but interpret personal issues subjectively according to their emotions and desires. Sometimes they begin with logical reasoning that ends in an emotionally driven conclusion (Interviews 16, 24).
A majority of Gen Zers seem to be ignorant and unconcerned about worldview because it is not a practical and imminent issue to them. Not only the Gen Zers, but also the religious educators who were interviewed affirmed that Gen Zers do not give much thought to the fundamental issues related to worldview (Interviews 13, 17, 21, 27). In this condition, the metaphysical and supernatural dimensions remain disconnected to the natural dimensions, resulting in a distorted worldview mixed inconsistently with external sources.

These characteristics are hard to understand and accept on the part of Gen X educators. The Gen $\mathrm{Z}$ worldview is often a mixture of modern and postmodern worldviews, whereas the Gen X worldview seems to be a mixture of pre-modern (or traditional) and modern (Enlightenment) worldviews. The overall characteristic of the Gen $\mathrm{Z}$ worldview, however, is heterogeneity, which was explicated in the mixture of heterogeneous worldviews expressed in the interviews. The diversity of viewpoints on many issues was emphasized in the interviews. This can rightly be called syncretistic scientism in the sense that it exists not as a uniform worldview, but in varying forms due to the mixtures.

What is important in practice is to defer with respect to the differences between the different generations. To ontologically differentiate is a good starting point for mutual understanding, which is the central concept that emerged in the process of this data analysis. The key word is faith in this mission. To have faith respectfully in one another is essential to overcome the differences. The result of the data analysis up to this point is summarized in Table 2 .

Table 2. Focused coding-worldview.

\begin{tabular}{llll}
\hline Process & Category & Theme (repeated) & Central concept \\
\hline Initial coding & General & $23(12)$ & To phenomenologically understand differences \\
Focused coding & Worldview & $18(11)$ & To ontologically differentiate \\
\hline
\end{tabular}

\subsubsection{Plausibility Structure}

The plausibility structure is directly linked to the function of worldview. When people judge the plausibility of a certain truth claim, they are affected by their worldview both directly and indirectly. The fundamental worldview themes affect the direction of epistemological process and the characteristics of the plausibility structure.

In this study, the issue of plausibility structure was analyzed with the data gathered through the second research question and its probes. A total of 29 codes belong to this category. Of them, 16 were repeated by three or more of the interviewees, to which the analytical process gave focused attention, while the remaining less-repeated codes were also considered in analysis for reference.

Gen Zers find it hard to make decisions on their own. Their decisions for marriage, future career, and other critical issues are never easy (Interviews 22, 28, 29). Their dependence on their parents hinders their independent decision-making (Interview 23). Overall, they are cautious about value judgments and lack coherence in making decisions according to their values and worldview (Interviews 21, 24, 25, 28). Four interviewees directly commented on this kind of decision disorder, and two more said their criteria of judgment were blurred or conflicting with one another.

Many Gen Zers' decision-making seems to be monolithically based (Interview 13). They are liable to make poor decisions affected by stimulating but inaccurate information and news (Interview 14). Sometimes when there is no ruling value system, they lack consistency in making decisions. For instance, their decisions on expenditure are inconsistent with their scientistic worldview. Moreover, the immediate input of information and stimuli can affect their whimsical decision-making, which is particularly noticeable to older people. One Christian educator pointed out that Gen Zers seem to be more vulnerable to heretical teachings due to this tendency of monolithic decision-making (Interview 28).

The tendency has to do with selective attention and inattention. Gen Zers make a quick decision on whether or not to spend time and give attention to an issue (Interview 28). If the issue does not interest them, they do not pay 
attention even though it might be helpful indirectly. Many decisions are dependent on which areas the Gen Zers are driven and exposed in regarding their information flow and learning (Interview 27). This kind of selective attention and inattention is attributed to the inundation of information and confusion from it. Gen Zers are not quite certain about their standpoint. One counselor, who has cared for young people in this generation for about 18 years, observed that they lack autonomy although they look independent outwardly (Interview 24).

Gen Zers could be described as subjective instead of objective in their judgment. Mixed with the emotionalism of the postmodern popular culture, they judge things based too much on personal likes and dislikes (Interviews 17, 26). One religious educator even asserted that most of the foundation for judging truth claims is emotionally driven (Interview 17)[18]. This subjectivity leads to religious pluralism as a practical solution for coexistence of competing religious traditions with many Gen Zers averse to interfering in other's religious standpoints (Interviews 17, 20). In other words, they try to understand and respect diverse religious standpoints as they are. They also believe that the position of nonreligious perspectives should be respected equally. Six of the interviewed Gen Zers explicated this kind of pluralistic position. People in this generation generally do not like to be strongly influenced by others on religious matters, which could be interpreted as a nihilistic phenomenon when they give up clarity to harmonize dissonant religious voices within their cognition. This aspect seems to reflect another facet of syncretistic scientism that is mixed with postmodern deconstruction.

Gen Zers tend to value public interest, emphasizing the importance of observing laws and regulations (Interviews 3, $4,8,15)$. Whether something is benefiting to others or not is important to many Gen Zers. They generally believe that a reasonable path to God should always be beneficial to people (Interview 4). A plausible truth claim should be edifying and contribute to the general good of society. To be good is central when there are multiple positions that seem to sound equally valid and convincing (Interview 8).

To be ethical is another important barometer for judging plausibility. Some Gen Zers seem to emphasize ethics more than the previous generations. They are concerned about human rights and ethical issues in more detail (Interviews 7, $10,14,15,21)$. In their opinion, ethical standards to prevent harmful antisocial damages should be respected and observed. A total of five interviewees emphasized this point a lot. Another five highlighted the culture of anonymity among Gen Zers in the sense that they do not like to disclose their identity unnecessarily. They do not like to disclose their religious identity and in some cases even their church attendance. From analysis, this seems to be a defense mechanism against the violation of privacy because for many Gen Zers, protecting privacy and personal rights comes before many other issues.

The scientistic orientation is continued in the decisionmaking of Gen Zers. Yet Gen Zers are not always rational and logical in making decisions, often doing so considering other factors. Other people's opinions also impact their decisions, with the majority opinions carrying more weight. But what counts most is what they really want, which is particularly true in the everyday decision-making (Interview 7).

When it comes to deciding which media to learn by, many in this generation prefer YouTube and other forms of $\mathrm{VoD}$ (Interviews 17, 21). Such audiovisual media are most preferred as a channel for learning. Instagram is also favored as a channel for self-expression and sharing views. Nevertheless, print media is still considered effective in learning expert knowledge (Interviews 1, 3, 6, 16). Some Gen Zers trust printed material more than video material as a knowledge source, with at least four interviewees thinking in this line.

For Gen Zers in South Korea, a key point in determining plausibility is checking the logical consistency or coherence. Logical congruence is a critical parameter of plausibility for many Gen Zers (Interviews 1, 11). This is one reason why religious messages are not heard when they are delivered without good reasoning (Interview 11). It is important to articulate and deliver truth claims based on good reasoning and argumentations. One interviewee expressed a discomfort and even antipathy towards distorted religious messages that only appeal to popular desires for materialistic blessings based on the prosperity gospel (Interview 1). A logically congruent message or truth claim is natural and easy to accept since it brings about trust on the part of the recipient.

For Gen Zers, it is also important to refer to the feedback of other people, especially those who are in a similar situation. Peer feedback is a viable option to check the plausibility of things. Many Gen Zers are conscious of others' different views, and they think it is wise to take them into consideration. Some find it uncomfortable to find their friends are very different from them, but still welcome their feedback.

Cultural backgrounds definitely affect the plausibility structure. There is a collective dimension in the formation of the plausibility structure, regardless of the individual differences, because certain collective and cultural aspects are shared in common. This has to do with education more than anything else, for the educational system and culture have impact on the formation of the plausibility structure.

One thing that characterizes Gen Zers' learning style is that self-motivation and initiatives are valued, so it is important for educators to facilitate the learners' motivation and initiative to learn. One-directional styles of teaching do not work effectively with this generation of learners (Interview 23), and this is even more so when it comes to religious education. Some Christians who experienced a religious awakening pointed out the importance of this experiential learning.

The experiential dimension is not only important on the part of the learners, but also on the part of the educators in that they need to teach by sharing their personal religious experiences. Even in the case of preaching a sermon, there 
should be an internally touching experience for the listeners (Interview 7). The religious messages can deliver more realistic contents when they are conveyed through experiential narratives (Interviews 4, 12). Especially testimonies of people who have overcome hardships in life are edifying to the listeners (Interview 12). Shared stories bridge the gap between the teacher and the learner, effectively crossing barriers set by differences in worldview. Storytelling seems to connect dissonant plausibility structures.

One experienced educator also pointed out the effectiveness of letting the trainees experience life by practicing certain things firsthand (Interview 22). This mode of experiential learning complements cognitive learning methods (Interview 26). The educators need to find ways to facilitate the participation of the learners to activate this mode of experiential learning. Nine interviewees emphasized this point in religious education.

Five interviewees evaluated Christian overseas outreach programs very positively. Both the pre-field preparatory process and field activities in a foreign country were considered worthwhile and satisfactory. They delayed many things in their career to participate, but considered it rewarding for the experiential learning through the intercultural exposure programs (Interviews 4, 23, 28). They preferred this way of learning by doing.

It is important to secure a friendly and comfortable atmosphere for the education of Gen Z. A burdensome atmosphere may inhibit their participation. An experienced religious educator defined her role as a friendly coach who guides the learners comfortably, and she tries to prepare good questions to talk with the young people (Interview 29). Building trust is at the core of such effort to narrow the gap. It may be a universal truth that can be applied to every generation, but is critical for Gen Zers in a world where there are too many dissonant voices conflicting with one another. Authenticity is a critical virtue not only for a religious educator, but also for a religious community (Interview 26). Four people affirmed this point in their interview.

Different generations might be dissonant in their plausibility structures, reflecting the characteristics of different worldviews. Understanding the differences based on a dispassionate description is important before passing any judgment. It is important to know that questions on epistemology are never binary, although there is the need to recognize firm ontological presuppositions. It is necessary to find epistemological contact points to effectively communicate with Gen Zers at a deep level, which is a central concept that emerged through this data analysis. The dissonance in plausibility structure at both individual and collective levels needs to be considered in addressing the issue of making contact points. The key word is hope. In order to narrow the gap between different plausibility structures, religious educators need to hope for an incarnational identification crossing barriers of dissonance in way of thinking. Building trust, respecting different styles of learning, and identifying creative contact points are key elements in hoping for incarnational boundary-crossing. The result of the data analysis up to this point is summarized in Table 3 .

Table 3. Focused coding--plausibility structure.

\begin{tabular}{llll}
\hline Process & Category & Theme (repeated) & Central concept \\
\hline Initial coding & General & $23(12)$ & To phenomenologically understand differences \\
Focused coding & Worldview & $18(11)$ & To ontologically differentiate \\
Focused coding & Plausibility structure & $29(16)$ & To epistemologically identify contact points \\
\hline
\end{tabular}

\subsubsection{Christian Worldview Education}

Efforts for worldview education from a Christian perspective essentially need to be based on the epistemological contact point. At the same time, they also need to move forward in addressing the various issues identified above. A detailed argumentation to deal with the raised issues is necessary for this.

A total of 26 codes were grouped together in the category belonging to the domains of research question three. Of them, 19 were repeated by three or more interviewees. These codes were primarily considered in data analysis, although other less frequent themes were also included.

One of the key issues in addressing the phenomena of syncretistic scientism is the loss or separation of a metaphysical dimension in the worldview formation. Educators observe that Gen Zers tend to reflect a weak understanding of this issue, while keeping up with scientistic issues well. To many Gen Zers, metaphysical argumentations are like wearing unfit clothes and a strange task to do (Interview 25). Many of them are incomplete in their formation and still in the process of dealing with this kind of work. Five educators agreed on this point, particularly one experienced educator suggesting that even in this process of addressing the metaphysical issue, experiential learning is effective. If it is related to the creation of the world, Gen Zers need firsthand experience of the natural world while meditating on the issue (Interview 23).

Personal experiences of a worldview clash are helpful in refining one's overall view of reality. Experiencing the clash of science and faith, some Christian Gen Zers choose to apply religious guidelines to integrate the worldview themes (Interviews 1, 2, 3, 6). To some of the Gen Z participants, asking questions was helpful in stimulating the much needed metaphysical reflections.

In order to systematically facilitate this process of learning, Christian educators need to apply new approaches and methods in their worldview education programs. Eight of the interviewed educators pointed to this need, emphasizing the limitation of existing programs and methods. Some of them added that the existing texts for biblical education are too difficult to understand on the part of Gen Zers. One reason 
the texts are considered difficult seems to be that they lack detailed explanations. Factual information and explanations need to be provided carefully in order to make the messages well-grounded and truthful. It is important to rigorously and solidly lay the foundation of certain claims as has been explained earlier.

On the other hand, the new methods of religious education need to be delivered in image languages and participatory modes to make them more understandable (Interview 29). The curricula for such education need to be clear in their focus on each section and content (Interview 7). Some churches and organizations are better prepared in attempting this kind of work, so they need to share their expertise with others that are smaller and inexperienced.

New approaches in Bible study programs need to be customized to make them relevant and effective to individual learners. The reason why some of the participants find them difficult to follow is that they are ready-made instead of customized to the individual's level. Complete customization might be unrealistic, but they need to adjust the programs to individual needs as much as possible (Interviews 2, 27). Individual mentoring is also helpful in facilitating reflections on the Christian teachings on a particular issue, according to a Christian Gen Zer (Interview 4). It is also important for Gen Zers to be able to ask questions before God and share their concerns with mature religious people (Interview 24). A dialogical approach is very effective with Gen Zers, which can be applied to worldview education focusing on this generation. Storytelling can be adopted in preaching and many other educational programs. Christian educators should be able to utilize different approaches in order to effectively empathize and communicate with this young generation (Interview 23).

The ability to deliver biblically-based messages through advanced media is critical in this age. The willingness to adjust to the changing demands and preferences is an important virtue expected of religious educators. Userfriendliness is required in reaching this generation with messages of the Bible (Interviews 9, 18). In particular, their preference for image languages needs to be considered in accommodating to such needs (Interviews 21. 28. 29). Gen Zers often begin to subscribe to a YouTube channel upon the recommendation of another reliable person (Interview 17). Christian educators who teach the Christian worldview need to be a good source of reference online.

The exclusive mentality of some Christians gets in the way of mutual understanding between Christians and nonChristians. Sometimes Christians are considered rude to followers of other religions or nonreligious people (Interview 20). On the other hand, Christians have a kind of segregating solidarity within their religious communities (Interviews 6, 19). They need to be more considerate and hospitable toward people who are new to the community of faith.

When churches and Christian organizations are uncooperative to public policies, they are even considered antisocial. During the Covid-19 pandemic, some churches and Christian organizations were reported as being uncooperative to government policies, and there were severe criticisms from the general public, some of which were voiced by the interviewees. A total of five participants directly commented on this matter. One university student who shared her negative impressions on the church she used to attend expressed how she was disappointed by some churches' unwillingness to abide by the government guidelines on the Covid-19 pandemic (Interview 20). A few Christian educators emphasized the urgent need for church reforms in face of lost credibility due to some scandals of church leaders.

A significant number of Gen Zers expressed their dislike for street evangelism, considering many of the evangelists' messages to be unreasonable and unacceptable; they were burdensome to hear at the least. Sometimes such practices were associated with the images of deviated groups not accepted by mainstream churches (Interview 20). One university student shared how he was emotionally wounded by an evangelist who coerced him to listen to the message when he was a child (Interview 17). Some universities have regulations to prevent evangelistic activities on their campus, to which different responses were expressed during the interviews. Still, it is important for Christian leaders to be sensitive to how their ways of evangelistic outreaches are received.

One-directional approaches do not seem to be well received in general. Often, more nuanced approaches are more effective. Evangelistic messages seem to be effective when delivered between peers, according to several interviewees. This is because they tend to be natural and positive in content and approach (Interview 14). Therefore, significant breakthroughs in reaching this generation on religion could be expected if initiated by this generation (Interview 21).

One obstacle to overcome is legalism. There are a lot of religious messages that are legalistic and hurtful to the listeners. A spirit of perfectionism is received as judgmental to this generation (Interviews 5, 24). Gen Zers need to hear messages of consolation and encouragement (Interviews 8 , 10, 22). One experienced Christian educator put it that this generation needs cheer-ups (Interview 22). Christian educators need to show how they wholeheartedly support those who come to them. They need to explain what they teach with patience and clarity. A total of nine interviewees pointed this out.

Integrating faith and life seems to be the core effort to be made, according to many Gen Zers. When faith is expressed authentically, people respond more willingly (Interviews 5, 26). Altogether, 11 of the interviewees affirmed this basic Christian teaching. Several of the university students shared how they were blessed and impacted by their religious educators who mentored them well showing integrity of faith and life. They said their religious backbone was strengthened through the mentoring relationship (Interviews 1, 2, 23).

Encouraging Gen Zers to be part of a religious community requires much wisdom and sensitivity. People like to get together in a community when it is safe and 
comfortable (Interview 26). Retreat programs are effective in terms of exposure to a communal atmosphere and fellowship. It is important to be respectful of the individualistic orientation when inviting Gen Zers to communal activities. Caring for the young people individually should accompany the communal fellowship and activities (Interview 2).

Gen Zers are observant about how religious teachings are practiced by their teachers (Interviews 6, 7, 24, 30). Teaching by practicing is normative, and influencing through everyday life is most viable (Interview 21). It takes a more personal touch to impact the lives of Gen Z (Interview 26). Eight people asserted this point during the interviews.

Many churches and Christian organizations serve and carry out activities by way of practicing God's love in the world. Several of the interviewees confirmed that this kind of effort is improving the public image of Christianity in South Korea. The sacrificial efforts of churches and Christian organizations positively influence the general public's view of Korean Christianity. Gen Zers are so trained for collaboration that they expect a similar level of willingness and competency for collaboration when part of a religious community (Interview 25). A sacrificial and cooperative spirit is important to this young generation.

What then might be the ultimate link in bridging the gaps between Christians and non-Christians and between Gen X and Gen Z? Among the many insights gleaned through the interviews, love seems to be considered the highest value for judgment. Two Gen Zers directly emphasized this point (Interviews 3, 5). Whether there is love or not is the ultimate parameter to determine the authenticity, health, and maturity of a religious worldview practiced by a religious group. Approaches based on love bridge the gaps between worldviews, plausibility structures, and generational cultures. Effort should be made for educational bridging with love between the separated beings, which is the central concept that emerged through the analyzed data. Educational bridging needs multiple or integrated approaches that reflect the heterogeneous and dissonant characteristics of the ontology and epistemology of Gen Z. It takes love to courageously go the extra mile and use advanced educational means to reach Gen $\mathrm{Z}$ with religious messages, even though they are unfamiliar to the educators. Love is the key word here. Love is and is to be both the spirit of the messenger and the content of the message in worldview education. The result of the data analysis up to this point is summarized in Table 4.

Table 4. Focused coding-worldview education.

\begin{tabular}{llll}
\hline Process & Category & Theme (repeated) & Central concept \\
\hline Initial coding & General & $23(12)$ & To phenomenologically understand differences \\
Focused coding & Worldview & $18(11)$ & To ontologically differentiate \\
Focused coding & Plausibility structure & $29(16)$ & To epistemologically identify contact points \\
Focused coding & Worldview Education & $26(19)$ & To educationally bridge the gaps \\
\hline
\end{tabular}

\subsection{Theoretical Coding and Theorizing}

The key words that summarized the data analyses above are also the key words for theoretical coding. They are the theoretical points: to ontologically differentiate between the generations that are different at the worldview level; to epistemologically identify contact points with crossgenerational norms and values; and to educationally bridge the gaps with the spirit and message of love. These tasks need faith, hope, and love. Faith is the key concept in the ontological mission of differentiation and respect. Hope is the key concept in the process of making epistemological contacts. Love is the key concept in the educational task of reaching Gen $\mathrm{Z}$ with the Christian message.

To have faith in one another respectfully is an essential attitude to overcome the ontological differences at the worldview level. It is a prerequisite in approaching a new generation with religious messages, to build a trusting and lasting relationship between generations that are too heterogeneous to be grouped together as a generation. Individual idiosyncrasies need to be respectfully considered. It takes a dispassionate description and an accurate understanding based on it before passing any ontological evaluation to reach Gen $\mathrm{Z}$ with religious messages.

To hope for incarnational identification by building trust, respecting different styles of learning, and identifying creative contact points are key elements in overcoming dissonance in plausibility structures. Incarnational identification will be possible when different and dissonant frames of reference are respected and reflected in making contact points. This kind of attitude is impressive and effective since it contains cross-generational norms and values shared by different generations with dissonant plausibility structures.

To love is the ultimate spirit, essence, and message of a Christian worldview that can bridge the gap of ontology and epistemology. In educational programs, a spirit of love that enables patience until the learners respond enthusiastically is much needed, although they are never the same in ontological and epistemological standpoints. In educational outreach, the message of love touches souls most powerfully, overcoming heterogeneities and dissonances. To show how the Christian worldview genuinely teaches love is the core message. Love is the very essence of the Christian worldview.

The missional tasks of ontology, epistemology, and education are not separate, but interconnected. To have integral faith, hope, and love is the essence of the Christian worldview and message, and the central concept that emerged when analyzing the data in this study. The result of the complete data analysis is summarized in Table 5. 
Table 5. Theoretical coding.

\begin{tabular}{llll}
\hline Process & Category & Theme (repeated) & Central concept \\
\hline Initial coding & General & $23(12)$ & To phenomenologically understand differences \\
Focused coding & Worldview & $18(11)$ & To ontologically differentiate \\
Focused coding & Plausibility structure & $29(16)$ & To epistemologically identify contact points \\
Focused coding & Worldview Education & $26(19)$ & To educationally bridge the gaps \\
Theoretical coding & Total & $96(58)$ & To have integral faith, hope, and love \\
\hline
\end{tabular}

\section{Conclusion}

The dominant worldview of Gen $\mathrm{Z}$ is generally syncretistic scientism often mixed with postmodern deconstructionism. This is largely contrasting with the Gen X worldview that seems to be syncretistic scientism mixed with a pre-modern or traditional worldview. The nature of the worldviews tends to influence their adherents to justify their views. The issue is not necessarily of right or wrong, although there are uncompromising essentials in each worldview.

It is important to ontologically differentiate between the generations that are different at the worldview level. Faith is the key word in this mission of ontological differentiation and deferral amid varying versions of syncretistic worldviews characterized by their heterogeneity. It helps to reserve judgment and remain descriptive before arriving at a conclusion. Faith as an interpersonal attitude and virtue that facilitates relationship-building based on mutual understanding and respect. Not fearing the possibility of misunderstanding and rejection, Christian educators can approach an unfamiliar generation such as Gen $\mathrm{Z}$ with a spirit of faith and respect.

Dissonant plausibility structures need epistemological contact points, which can be identified in cross-generational norms and values. The essence of the task, however, is not just epistemological considering the multifaceted nature of the important plausibility structure from the beginning. Beyond epistemological tasks, what is needed is to attempt at incarnational identification based on identifying epistemological contact points amidst the clash of plausibility structures. Hope is the key word in this process. Incarnational identification is possible only when the religious educators hope and desire to ring a bell to the young souls in a meaningful and creative way. This is none other than missional passion. It is necessary to consider different plausibility structures to be relevant and heard.

A relevant worldview education needs educational bridging with the spirit and message of love. Love is the key word in this task of educational bridging. Christian educators need to teach the message of love in the spirit of love in order to help transform worldviews considering the heterogeneous and dissonant formations of worldviews and plausibility structures.

Faith, hope, and love, as exegeted in accordance with social scientific procedure, are the transcendental essence of the Christian worldview. These essential virtues can competently cross barriers of culture, generation, worldview, and plausibility structure. The mission of transforming worldviews can be fulfilled by teaching and practicing faith, hope, and love. Integrating these virtues in the outreach toward the new generation can be fruitful. An integral worldview of an educator can be multiplied in the lives of many no matter how different and unfamiliar they are.

"So now faith, hope, and love abide, these three; but the greatest of these is love." (1 Corinthians 13:13, English Standard Version).

\section{References}

[1] For a generational distinction in the United States, please refer to Pew Research Center. (2014). Religious Landscape Study. https://www.pewforum.org/religious-landscape-study/.

[2] Samjong KPMG. (2019). Samjong Insight 66, 1-36.

[3] Lee, G. and S. Park. (2018). Social Big Data Ro Bon Z Sedae. Card Business Brief by BC Card Digital Research Institute. 16.

[4] Shin, J. (2019). Millenial Sedae wa Z Sedae Media Iyong. KISDI STAT Report 19 (03), (15.02.2019). 1-9.

[5] Please refer to Clifford Geertz's explanation about the concept of worldview. Clifford Geertz, The Interpretation of Cultures, Basic Books, 1973, p. 127.

[6] Kearney's notion of worldview universals advanced the method of researching worldviews empirically to a significant degree. Michael Kearney, World View. Novato, CA: Chandler and Sharp Publishers, 1984, pp. 65-108.

[7] Hiebert's explanations on methods of analyzing worldviews are helpful and comprehensive. Paul G. Hiebert, Tranforming Worldviews: An Anthropological Understanding of How People Change. Grand Rapids: Baker Academic, 2008, pp. 89104.

[8] Peter L. Berger, The Sacred Canopy: Elements of a Sociological Theory of Religion. New York: Anchor Books, 1967, pp. 61-69, 189.

[9] Lesslie Newbigin, Foolishness to the Greeks: The Gospel and Western Culture. Grand Rapids, MI: Eerdmans, 1986, pp. 1011; Lesslie Newbigin, The Gospel in a Pluralist Society. Grand Rapids: Eerdmans, 1989, pp. 8-11.

[10] Barna Group and Impact 360 Institute, Gen Z: The Culture, Beliefs and Motivations Shaping the Next Generation, 2018.

[11] The author understands that the concept of plausibility structure is not merely epistemological. However, for the sake of a cognitive approach in the initial stage, this study starts by analyzing the epistemological issues, and then moves on to incorporate other related social realities comprehensively in the final analysis.

[12] Kathy Charmaz, Constructing Grounded Theory, 2nd Edition. LA: SAGE, 2014. pp. 109-224. 
[13] James Emery White, Meet Generation Z: Understanding and Reaching the New Post-Christian World. Grand Rapids: Baker Books, 2017, pp. 38-39, 51.

[14] It is interesting to note that Peter L. Berger also considered the phenomenon of the limited plausibility structure within the boundary of a nuclear family. Berger pointed out that the plausibility structure of a fragmented world can in some cases be no larger than the nuclear family. Please refer to Peter L. Berger, The Sacred Canopy: Elements of a Sociological Theory of Religion. New York: Anchor Books, 1967, p. 168.

[15] Richard Dool \& a team of Gen $Z$ co-authors, How Generation $\mathrm{Z}$ Wants to Be Led. Published by Richard Dool, 2019, pp. 141-142.
[16] Corey Seemiller and Meghan Grace Seemiller, Generation Z Learns: A Guide for Engaging Generation Z Students in Meaningful Learning. Independently published, 2019, pp. 4649.

[17] Mark Beal, Decoding Gen Z: 101 Lessons Generation Z will Teach Corporate America, Marketers \& Media, 2018, p. 1.

[18] It is interesting to note that Peter Berger has pointed out that as the plausibility structure disintegrated, and traditional religious contents can only be maintained in consciousness as "opinions" or "feelings". Peter L. Berger, The Sacred Canopy: Elements of a Sociological Theory of Religion. New York: Anchor Books, 1967, p. 187. 